\title{
Giovanna Angeli, Macchine meravigliose. Surrealismo e tecnologia
}

\section{Stefano Genetti}

\section{(2) OpenEdition}

1 Journals

\section{Edizione digitale}

URL: http://journals.openedition.org/studifrancesi/6081

DOI: 10.4000/studifrancesi.6081

ISSN: 2421-5856

Editore

Rosenberg \& Sellier

\section{Edizione cartacea}

Data di pubblicazione: 1 mai 2011

Paginazione: 208

ISSN: 0039-2944

\section{Notizia bibliografica digitale}

Stefano Genetti, «Giovanna Angeli, Macchine meravigliose. Surrealismo e tecnologia», Studi Francesi [Online], 163 (LV | I) | 2011, online dal 30 novembre 2015, consultato il 10 janvier 2021. URL: http:// journals.openedition.org/studifrancesi/6081 ; DOI: https://doi.org/10.4000/studifrancesi.6081

Questo documento è stato generato automaticamente il 10 janvier 2021.

\section{(c) (i) (9)}

Studi Francesi è distribuita con Licenza Creative Commons Attribuzione - Non commerciale - Non opere derivate 4.0 Internazionale. 


\title{
Giovanna Angeli, Macchine meravigliose. Surrealismo e tecnologia
}

\author{
Stefano Genetti
}

\section{NOTIZIA}

GIOVANNA ANGELI, Macchine meravigliose. Surrealismo e tecnologia, Firenze, Le Lettere, 2009

(«Saggi»), pp. 150.

1 Specialista del Surrealismo (al volume Surrealismo e umorismo nero si affiancano vari articoli fra cui, oltre a quelli qui rielaborati, André Breton e «le personnage fuyant de Mélusine». Da Nadja a Nadja, in Melusine, a cura di Anna Maria BABBI, Verona, Fiorini, 2009, pp. 237-248, dove figura anche lo studio di Greta REGGIANI, Rilettura di un mito: "Mélusine ou La robe de saphir" di Franz Hellens, pp. 215-236), G. Angeli dedica un libro avvincente, documentatissimo e riccamente illustrato, al fascino controverso esercitato dalla macchina. Controverso perché sotterraneo, marginale ma persistente, inconfessabile e, a tratti, sconfessato. Evocando l'accusa di retrivo antiprogressismo lanciata da J. Clair contro i surrealisti, l'A. ridimensiona la loro presunta avversione contro la tecnologia sondando, tra le pieghe della storia ufficiale del movimento, i «contraddittori percorsi» e le «incostanti configurazioni» di «una vera e propria esaltazione dell'elemento meccanico, ora considerato poeticamente, ora strappato al suo funzionamento e reso oggetto di culto, ora lasciato esplodere in fantasmagorie cinetiche» (p. 7).

2 Nelle tre parti che compongono il volume (Idolatrie macchiniste, Incontri fortuiti e Schermi surrealisti), l'A. tesse un fitto reticolo di filiazioni e rinvii intertestuali e interartistici. Accanto a scritti quali Locus solus di Roussel, la cui «deriva programmata» (p. 53) coniuga messa in scena di un tecnicismo "vistoso e [...] fine a se stesso» (p.44) ed esibizione di un ingranaggio affabulatorio parimenti autonomo e improduttivo, quali Hebdomeros di De Chirico, Le Paysan de Paris di Aragon o Nadja e L'Amour fou di Breton, sono oggetto di puntuali commenti o di cenni complementari svariati altri testi, verbali 
e visivi, pittorici, fotografici e filmici: gli anagrammi e aforismi di Duchamp e Desnos, le intitolazioni e didascalie incongrue di Picabia; i ritratti geometrici di M. de Zayas e i «dessins mécano-plastiques» (p.78) di Ernst, le macchine da scrivere trasfigurate da Domínguez e le macchine da cucire sessualizzate da Klapheck; il Ballet mécanique di Murphy e Léger, quest'ultimo durevolmente attratto dai congegni bellici, e La Marche des machines di Deslaw; gli esperimenti di Man Ray e le collaborazioni cinematografiche di Buñuel e Dalí; Metropolis di Lang, i vampiri di Murnau o di Dreyer e Tempi moderni di Chaplin, i poèmes cinematografici di Soupault e la sceneggiatura, mai girata, di Péret Pulchérie veut une auto o quella di Desnos per il documentario Records 37, assai diversa dalla versione realizzata.

Intorno all'immagine ricorrente dell'automobile lanciata ad alta velocità, all'erotizzazione della macchina e alla mitologia moderna dello spazio urbano, intorno al moltiplicarsi degli spunti creativi - riviste specializzate, manifesti pubblicitari e disegni tecnici - e al dibattito sul un cinema il cui «orizzonte ideale si situa [...] al confine fra la realtà e il sogno» (p. 114), intorno all'uso autoriflessivo della cinepresa e all'arte del montaggio, si affrontano le nozioni centrali di dépaysement, hasard objectif e trouvaille e si profilano, a monte come a valle delle avanguardie storiche, ramificate genealogie che vanno dal meccanicismo di La Mettrie ai romanzi di Verne, dal Coppelius di Hoffmann all'Ève future di Villiers de l'Isle-Adam, da Lautréamont a Kafka, da Apollinaire a Leiris e da Jarry a Queneau. Il confronto dinamico tra diversi atteggiamenti ideologici ed estetici di fronte ai prodigiosi ritrovati della tecnicavitalismo oppure astrattismo geometrico, entusiasmo oppure scetticismo, ora polemico ora parodico-comporta una «libera circolazione di modelli, incroci spontanei, convergenze e affinità di fantasie e di forme. Magari a dispetto degli stessi protagonisti» (p. 97). Problematizzando l'associazione di rigetto della scienza e culto dell'irrazionale e del primitivo, nonché la dialettica di progresso tecnologico e passione per la fabbricazione artigianale, il saggio di G. Angeli induce a ripensare, al di là di palesi derivazioni e fratture ostentate, i rapporti tra Futurismo, Dada e Surrealismo. 